\title{
ALK alteration is a frequent event in aggressive breast cancers
}

\author{
Abdul K. Siraj ${ }^{1 \dagger}$, Shaham Beg ${ }^{1 \dagger}$, Zeenath Jehan ${ }^{1}$, Sarita Prabhakaran ${ }^{1}$, Maqbool Ahmed ${ }^{1}$, Azhar R.Hussain ${ }^{1}$, \\ Fouad Al-Dayel ${ }^{2}$, Asma Tulbah², Dahish Ajarim ${ }^{3}$ and Khawla S. Al-Kuraya ${ }^{1,4^{*}}$
}

\begin{abstract}
Introduction: Breast cancer is the most common female malignancy worldwide and, despite improvements in treatment modalities, there are increased chances of recurrence and metastasis in a substantial number of cases and it remains one of the major causes of mortality among female cancer patients. Anaplastic lymphoma kinase (ALK) gene has been found to be altered in several solid and hematologic tumors. We aimed to comprehensively study the prevalence of ALK expression, and changes in copy number and translocation in a large cohort of breast cancer cases in a Middle Eastern population.
\end{abstract}

Methods: ALK protein expression was investigated by immunohistochemistry and numerical and structural variations of the ALK gene were analyzed by fluorescence in situ hybridization (FISH) in a tissue microarray format in a cohort of more than 1000 Middle Eastern breast cancers. The data were correlated with clinicopathologic parameters and other important molecular biomarkers.

Results: Immunohistochemical analysis showed ALK overexpression in $36.0 \%$ of the breast cancer patients and gene amplification was present in $13.3 \%$ of cases, seen by FISH analyses. ALK overexpression was significantly associated with ALK gene amplification $(p=0.0031)$. ALK-overexpressing tumors showed significant association with high-grade tumors $(p=0.0039)$, ductal histologic subtype $(p=0.0076)$, triple-negative phenotype $(p=0.0034)$, and high Ki-67 $(p=0.0001)$ and p-AKT $(p<0.0001)$.

Conclusions: Immunohistochemical analysis showed ALK is overexpressed in a substantial proportion of breast cancers and possibly plays a significant role in the aggressive behavior of this cancer. Gene amplification is hypothesized to be a possible cause for a significant proportion of this overexpression. Based on these findings, a potential role for an ALK inhibitor, as a therapeutic agent targeting aggressive subtypes of breast cancer, merits further investigation.

\section{Introduction}

Breast cancer is a heterogeneous group of diseases based on morphological features, molecular profiles, response to treatment and clinical outcome [1]. Every year, approximately 1.5 million women around the world are diagnosed with breast cancer [2]. It is the most common malignancy diagnosed among Saudi females [3] and is found to have an advanced stage, high grade and tends

\footnotetext{
* Correspondence: kkuraya@kfshrc.edu.sa

${ }^{\dagger}$ Equal contributors

'Department of Human Cancer Genomic Research, King Faisal Specialist Hospital and Research Center, Makkah Al Mukarramah Branch Road, Riyadh 12713, Saudi Arabia

${ }^{4}$ Department of Pathology, Al-Faisal University, Al Zahrawi Street, Riyadh 11533, Saudi Arabia

Full list of author information is available at the end of the article
}

to affect a younger population as compared to the West $[4,5]$. Despite improvement in treatment protocols and addition of new therapies, breast cancer continues to be the second leading cause of cancer mortality in women in the Western world [6]. Identification of new targeted therapy that allows progress in the management of breast cancer and improves survival is warranted.

Anaplastic lymphoma kinase (ALK), a tyrosine kinase receptor residing on chromosome 2 p23 was first described in a subset of anaplastic large cell lymphoma (ALCL) patients as part of a chromosomal rearrangement with nucleophosmin as a fusion partner [7]. ALK has been reported to be translocated with other fusion partners, such as KIF5B [8], NPM1 [7], RET, ROS [9], VCL [10], TFG [11], EML4 [12] and MYH9, demonstrating its role in the pathogenesis of various cancers. The
C Biomed Central

(C) 2015 Siraj et al. Open Access This article is distributed under the terms of the Creative Commons Attribution 4.0 International License (http://creativecommons.org/licenses/by/4.0/), which permits unrestricted use, distribution, and reproduction in any medium, provided you give appropriate credit to the original author(s) and the source, provide a link to the Creative Commons license, and indicate if changes were made. The Creative Commons Public Domain Dedication waiver (http://creativecommons.org/publicdomain/zero/1.0/) applies to the data made available in this article, unless otherwise stated. 
chimeric protein resulting from the fusion has lead to constitutively activated ALK tyrosine kinase [9, 10, 13]. Furthermore, other reports demonstrate additional modes of constitutively activated ALK kinase by mutations [14-16] and ALK gene amplification [17-19]. It has been suggested that the oncogenic role of ALK is most probably mediated via activation of tyrosine kinases that promote survival via activation of signaling pathways such as PI3kinase/AKT [20] or by inhibition of apoptosis, thus leading to proliferation of cells. It has been demonstrated that inhibition of ALK inhibits growth of breast cancer cell lines and also tumor xenografts in mouse models [21].

ALK alterations such as increased ALK copy number, gene amplification and translocation have been shown to be present in $80 \%$ of inflammatory breast cancer and 25 $\%$ of triple-negative breast cancers (TNBC), which are considered to be the most aggressive subtypes of breast cancers [21-23]. Moreover data generated from The Cancer Genome Atlas (TCGA) database on 479 breast cancer cases has also confirmed ALK deletions and copy number variations in breast tumors [21].

These known dysregulations in the ALK gene and their potential usefulness as biomarkers in many solid tumors, like inflammatory myofibroblastic tumors [24], esophageal squamous cell carcinoma [25] breast carcinoma [18] lung adenocarcinoma $[9,26]$ pediatric renal cell carcinoma [10] and neuroblastoma [27], have led to the development of ALK inhibitors and highlighted their therapeutic role in early clinical trials $[18,28,29]$. Crizotinib, an orally bioavailable tyrosine kinase inhibitor, has been shown to act against ALK kinase domain and is active against ALKexpressing tumors [24, 30,31]. These recent studies have provided evidence for the emerging role of ALK as a potential molecular marker of diagnostic and therapeutic value in breast cancer.

Thus we attempted to investigate the structural and numerical alterations of ALK by fluorescence in situ hybridization (FISH) and protein expression by immunohistochemistry (IHC) in a large cohort of Middle Eastern breast cancers. We further correlated ALK alterations with clinical data including survival analysis, pathological parameters and other molecular markers in breast cancer patients.

\section{Methods}

\section{Patient samples and data collection}

One thousand and nine patients with breast cancer diagnosed between 1990 and 2011 were selected from the files of the King Faisal Specialist Hospital and Research Centre (KFSHRC). The patients included in this study had their diagnosis, treatment and follow-up care in the Department of Surgical Oncology at KFSHRC. The histologic subtype of each breast tumor sample was determined according to World Health Organization (WHO) criteria. Waiver of consent was obtained for the study from the Institutional Review Board (IRB) and Research Ethics Committee (REC) of KFSHRC under Project RAC number 2040004 on breast cancer archival clinical samples. All samples were analyzed in a tissue microarray (TMA) format.

\section{Tissue microarray (TMA) construction}

For each tumor, representative areas were selected mapped and a TMA was constructed using these mapped slides as a reference. The tissue microarrayer (Semiautomated Arrayer, CM1 Mirlacher, Neuenburg, Germany) was used and $0.6 \mathrm{~mm}$ diameter punches were obtained from the donor blocks. A map of the recipient block was prepared with coordinates and a number for each sample to correctly identify the tumor. The punched-out tissue cores from the donor block were inserted in the recipient block. The array blocks were incubated at $45{ }^{\circ} \mathrm{C}$ for 10 minutes to improve adhesion between cores and paraffin of the recipient block. They were cut at room temperature with a standard microtome (Thermo Shandon, Runcorn, UK) and slides were prepared using a tape-sectioning system (Instrumedics, Inc., St. Louis, MO, USA).

IHC and FISH staining were done on TMA slides cut from two replicas of TMA blocks for scoring to reduce the number of non-interpretable spots. Both the ALK IHC and ALK FISH non-interpretable spots were within the range of $10 \%$ and the rest of the TMA spots were scored in concordance with earlier biomarker studies on TMAs [32].

\section{Fluorescence in situ hybridization (FISH)}

FISH assay for ALK amplification and rearrangement was performed on a TMA format. The probe (BAC clone) corresponding to the ALK gene was selected by browsing Ensembl Genome Browser [33] and were purchased from the Children's Hospital Oakland Research Institute (Oakland, CA USA). The BAC clone was cultured, DNA isolated and was labeled with digoxygenin (DIG) utilizing a DNA labeling kit from Roche (Roche, Hamburg, Germany). A commercially available centromeric probe for chromosome 2; CEP2 (Abbott Molecular, Abbott Park, IL, USA) was utilized as an internal control. FISH on a breast cancer TMA was performed as previously described [32]. Tissue samples were classified with an ALK/CEP2 ratio of 1.0 as normal; between 1.0 and 2.5 as having ALK gains; 2.5 and above as amplified [17]. A minimum of 25 cells were scored in a single microarray spot for the presence of both CEP2 and ALK signals. ALK gene amplifications and gains identified by the BAC clone RP11-328L16 were also further confirmed by the break-apart probe from Vysis (Abbott Molecular, Abbott Park, IL, USA) 
according to the manufacturer's instructions using a BX51 Olympus fluorescence microscope (Olympus, Richardson, TX, USA). Briefly, in a normal cell with no gain or amplification, two fused red and green signals were observed. Increase in the number of red and green fused signals were considered to be amplifications and gains. An ALK break-apart probe set was also used to check for ALK gene rearrangement on breast cancer TMA slides. ALK rearrangement was termed as positive if $>15 \%$ of tumor cells showed split red and green signals and/or single red signals in addition to a single fused signal; otherwise, the specimen was classified as ALK FISH negative [26].

FISH analysis using the ALK probe was also performed on eight breast cancer cell lines (Cal-120, HCC-1937, EFM-19, HDQ-PI, CAL-51, MT-3, MDA-MB231 and MCF-10).

\section{DNA isolation}

A Gentra DNA isolation kit (Gentra, Minneapolis, MN, USA) was utilized to extract DNA from paraffin-embedded breast cancer tissues using the manufacturer's recommendations as described previously [34].

\section{Quantitative real-time PCR}

The quantitative PCR (qPCR) technique was utilized to validate the copy number variation of the ALK gene observed by FISH. A few representatives DNA samples from formalin-fixed paraffin-embedded samples (FFPE) of breast cancer with normal and increased ALK copy number by FISH were selected for validation by quantitative real-time (qRT) PCR. DNA content was normalized to that of long interspersed element 1 (LINE1), a repetitive element for which copy number per haploid genome is similar in both the normal DNA sample and DNA from cancer cells. Primers were designed by Primer Express software v3.0 (Applied Biosystems, Foster City, CA) to hybridize to sequences of genomic DNA for ALK. The primers to the genomic sequences for ALK and LINE1 are as follows:

\section{ALK forward: CTT TGA CTT CCC CTG TGA GC ALK reverse: GCA GCC TCT CCC TTA CCT C LINE1 forward: CCG CTC AAC TAC ATG GAAACT G LINE1 reverse: GCG TCC CAG AGATTC TGG TAT G}

The PCR conditions and Light Cycler PCR protocol were used as previously described [35]. The Pfaffl method for relative quantification was used to calculate the fold change for breast cancer samples that showed normal copy number and amplification of ALK gene [36].

\section{Immunohistochemistry}

For IHC staining, TMA slides were processed and stained manually as described earlier [36]. A list of antibodies and their dilutions are listed in Table S1 in Additional file 1. For ALK IHC, primary ALK antibody (cloneD5F3; CST; 1:100 dilutions; Dako Target Retrieval pH9) was applied and incubated overnight. Visualization of the antigen antibody reaction was done using an enhanced polymer-based detection system, Envision Plus Dual Link System-HRP for 1 hour. Diaminobenzidene (Dako, Glostrup, Denmark) was employed for 5 minutes as the chromogen. A known CD30-positive ALCL case was utilized as a positive control and the negative control used was a mouse immunoglobulin G1 serum substitution for the primary antibody (ALK) [37]. The cutoff for estrogen receptor (ER) and progesterone receptor (PR) was taken as $1 \%$ nuclear staining. Human epidermal growth factor receptor 2 (HER2) overexpression was assessed according to American Society of Clinical Oncology/College of American Pathologists (ASCO/CAP) guidelines [38]. The cutoff for high Ki67 was taken as more than $10 \%$ nuclear staining [39]. For p-AKT immunoscoring only intensity scores were considered. Tumors with intensity $2+/ 3+$ were considered positive and intensity $0 / 1+$ were taken as negative [40].

For ALK IHC H-score (range 0-300) was obtained by adding the sum of scores obtained for each intensity and proportion of area stained [35]. X-tile plots were constructed for assessment of biomarker and optimization of cutoff points based on outcome as has been described earlier [41]. Breast cancers were categorized into two groups based on X-tile plots: one with complete absence $(\mathrm{H}$ score $=0)$ and the other with ALK expression (H score $>0$ ).

Two pathologists (SB and SP) independently performed IHC scoring for biomarkers and for discrepant scores consensus was established by reviewing the slides together.

\section{Cell lysis and immunoblotting}

Proteins from MDA-MB231 and MCF-12A cells were isolated as described previously [42]. Twenty micrograms of isolated proteins were separated by SDS-PAGE and transferred to polyvinylidene difluoride (PVDF) membrane (Immobilon, EMD Millipore, Billerica, MA, USA). Immunoblotting was performed using ALK (Santa Cruz Biotechnology Inc., Dallas, TX, USA) and betaactin (Cell Signaling Technology, Boston, MA, USA) antibodies and visualized by the enhanced chemiluminescence (Amersham, Pittsburg, PA, USA) method.

\section{Preparation of cytosolic and nuclear extract}

MDA-MB231 and MCF12A cells were suspended in buffer A containing $10 \mathrm{mM}$ HEPES, $10 \mathrm{mM} \mathrm{KCl}, 0.1 \mathrm{mM}$ EDTA, $0.1 \mathrm{mM}$ EGTA, 1mM DTT and the recommended amount 
of protease inhibitors and incubated on ice for 15 minutes. After incubation, cells were lysed with $10 \%$ NP-40 and vortexed for 10 seconds. Cells were spun for 30 seconds at $14,000 \mathrm{rpm}$ and supernatants containing nuclear-free cytosolic extracts were isolated. The remaining pellet was lysed in protein lysis buffer containing $0.4 \mathrm{mM} \mathrm{NaCl}$ and nuclear extracts were isolated. Twenty micrograms of isolated proteins were separated by SDS-PAGE and transferred to polyvinylidene difluoride (PVDF) membrane (Immobilon, EMD Millipore, Billerica, MA, USA). Immunoblotting were performed using ALK and alpha-tubulin (Cell Signaling Technology, Boston, MA, USA) antibodies and visualized by the enhanced chemiluminescence (Amersham, Pittsburg, PA, USA) method.

\section{Statistical analysis}

The JMP 10.0 (SAS Institute Inc., Cary, NC, USA) software package was used for data analyses. We examined the association of TNBC with clinicopathologic parameters, biomarker expression and also performed survival analysis. Survival curves were generated using the KaplanMeier method with significance evaluated using the Mantel-Cox log-rank test. Risk ratio was calculated using the Cox proportional hazard model. Values of $p<0.05$ were considered statistically significant.

\section{Results}

\section{Clinicopathologic data}

The clinicopathologic characteristics of the 1009 breast cancer patients are summarized in Table 1 . The median age at the time of surgery was 46 years (interquartile range [IQR], 39.0-54.0 years). The median length of follow-up available for surviving patients was 53.0 months (IQR, 30-77 months). The 5-year overall survival for the study population was $80 \%$. The distribution of tumors by histologic type was as follows: 918 infiltrating ductal carcinomas (91.0\%), 46 infiltrating lobular carcinomas (4.6\%), 16 mucinous cancers (1.6\%) and 29 $(2.9 \%)$ others. TNM staging was performed as per WHO criteria. The majority of the patients were in stage II $(37.7 \%)$ at time of diagnosis followed by stage III (30.8\%), stage IV (9.1\%) and stage 1 (7.5\%).

\section{ALK protein expression by IHC and correlation with clinicopathologic features}

Of the 1009 breast cancer cases investigated, $36.0 \%$ (350/972) of cases showed positive staining of ALK by IHC. Thirty-seven cases were non-interpretable due to loss of tissue cores or absent tumor cells in the core. The staining pattern ranged from an intense $3+$ staining in the cytoplasm and/or membrane to $2+$ moderate cytoplasmic staining and no cytoplasmic staining. A small subset of breast tumors (3.2 \%) showed punctate coarse granular cytoplasmic staining (Fig. 1a-d). ALK
Table 1 Clinicopathologic variables for the breast cancer patient cohort $(n=1009)$

\begin{tabular}{ll}
\hline Age & \\
\hline Median & 46.0 \\
Range (IQR)^ & $39.0-54.0$ \\
Histologic type & \\
Infiltrating ductal carcinoma & $918(91.0)$ \\
Infiltrating lobular carcinoma & $46(4.6)$ \\
Mucinous carcinoma & $16(1.6)$ \\
Other subtype carcinoma & $29(2.9)$ \\
Histologic grade & \\
Well differentiated & $73(7.2)$ \\
Moderately differentiated & $484(48.0)$ \\
Poorly differentiated & $397(39.3)$ \\
Unknown & $55(5.5)$ \\
Lymph node status & \\
Positive & $627(62.1)$ \\
Negative & $306(30.3)$ \\
Unknown & $76(7.5)$ \\
TNM stage & \\
I & $76(7.5)$ \\
II & $378(37.7)$ \\
III & $314(30.8)$ \\
\hline
\end{tabular}

Anterquartile range (IQR)

expression was found to be significantly associated with poorly differentiated tumor $(p=0.0039)$, infiltrating ductal carcinoma subtype $(p=0.0076)$ and triple-negative breast cancer $(p=0.0034)$; however, no association was seen with age, lymph node involvement, distant metastasis and tumor stage. ALK expression was also found to be significantly associated with Ki-67 expression $(p=0.0001)$ and p-AKT $(p<0.0001)$. (Table 2, Fig. 1e,f).

We also performed biochemical fractionation in breast cancer cell lines using nuclear and cytoplasmic extracts and found ALK expression to be more pronounced in cytosolic fraction (Figure S1 in Additional file 2) and had comparatively more expression in the triple-negative cell line compared to the non-tumorigenic epithelial breast cell line; MCF12A (Figure S2 in Additional file 3).

\section{ALK copy number alterations and translocations}

Numerical and structural abnormalities were analyzed by FISH in our cohort of 1009 breast cancer patients. A total of 980 spots out of 1009 showed interpretable results and 29 spots were non-interpretable due to absence of interpretable signals or loss of tissue spots. A total of $13.3 \%$ cases (130/980) showed amplification of ALK 


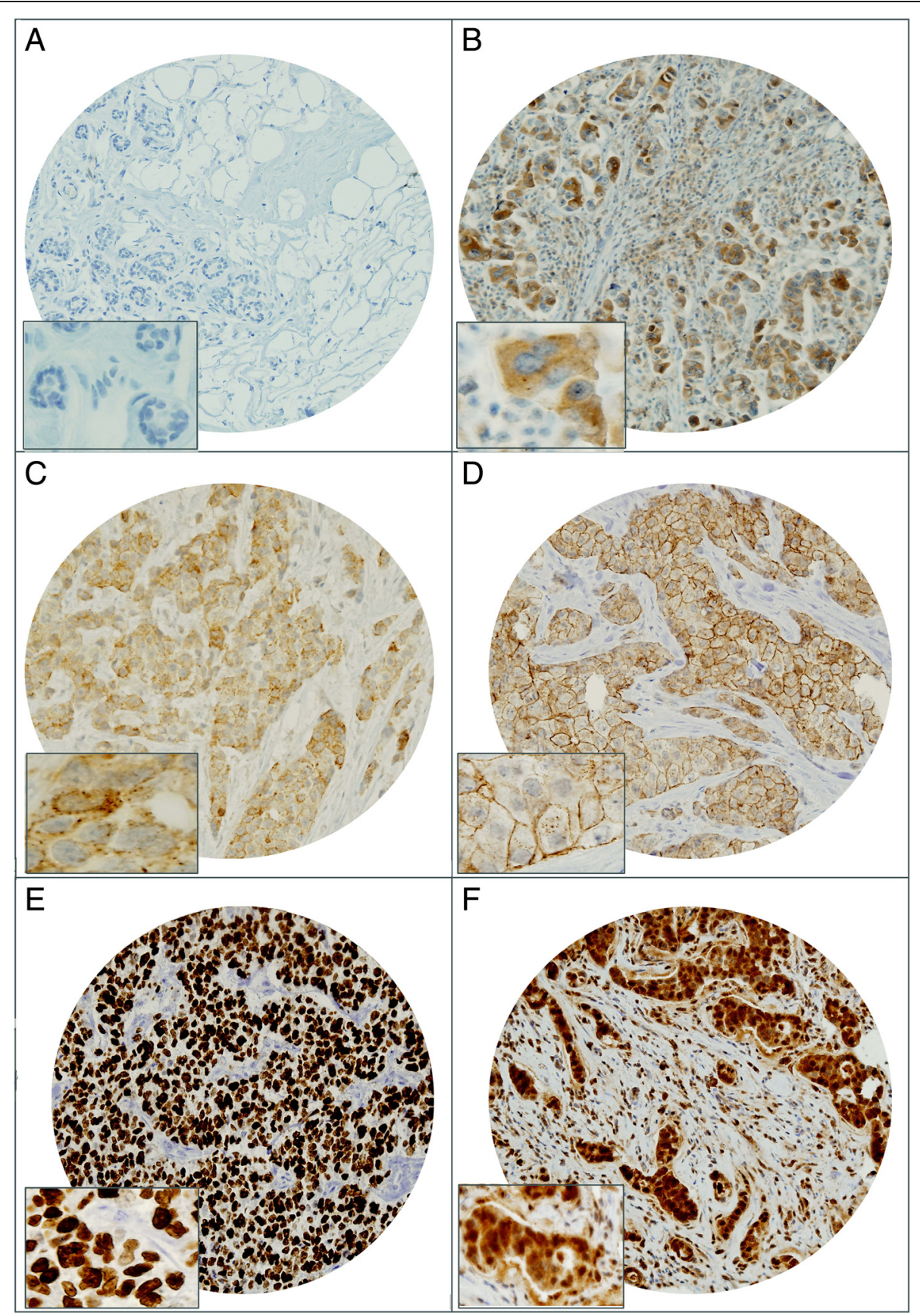

Fig. 1 Tissue microarray-based immunohistochemical analysis of ALK in breast cancer patients. a Normal breast tissue showing negative ALK expression. b Breast cancer TMA spot showing ALK overexpression in cytoplasmic compartment. Inset is higher magnification (40x) view showing absence of nuclear staining. c Breast cancer TMA spot showing granular dot-like ALK staining in cytoplasmic compartment. d Breast cancer TMA spot showing membranous ALK staining in cancer tissue. e Breast cancer tissue array spots showing high proliferative index of Ki-67. $\mathbf{f}$ Breast cancer TMA spot showing p-AKT overexpression. 20 ×/0.70 objective on an Olympus BX 51 microscope (Olympus America Inc, Center Valley, PA, USA) with the inset showing a 40× 0.85 aperture magnified view of the same. ALK anaplastic lymphoma kinase, TMA tissue microarray

gene (Fig. 2a-d). Amplification was observed in at least $30 \%$ of the cells analyzed. We found ALK copy number gains in 70/980 (7.1\%) cases analyzed. In the majority of these cases, gains were seen in at least $30 \%$ of the tumor cells. We also investigated the presence of
EML4-ALK fusion by FISH and found no translocation of these two genes. In addition, we also did not observe any ALK gene amplification in six breast cancer cell lines (Cal-120, EFM-19, HDQ-PI, CAL-51, MT-3, and MCF-10) analyzed, however, two cell lines (HCC-1937 
Table 2 Correlation of ALK IHC with clinicopathologic parameters in breast cancer

\begin{tabular}{|c|c|c|c|c|c|c|c|}
\hline & \multicolumn{2}{|l|}{ Total } & \multicolumn{2}{|c|}{ ALK present } & \multicolumn{2}{|c|}{ ALK absent } & \multirow[t]{2}{*}{$P$ value } \\
\hline & $\mathrm{N}$ & $\%$ & $\mathrm{~N}$ & $\%$ & $\mathrm{~N}$ & $\%$ & \\
\hline Total number of cases & 972 & & 350 & 36.0 & 622 & 64.0 & \\
\hline \multicolumn{8}{|l|}{ Age groups } \\
\hline$<50$ & 663 & 68.2 & 250 & 37.7 & 413 & 62.3 & \multirow[t]{2}{*}{0.1044} \\
\hline$\geq 50$ & 309 & 31.8 & 100 & 32.4 & 209 & 67.6 & \\
\hline \multicolumn{8}{|l|}{ Lymph nodes } \\
\hline NO & 300 & 32.9 & 108 & 36.0 & 192 & 64.0 & \multirow[t]{4}{*}{0.5832} \\
\hline $\mathrm{N} 1$ & 294 & 32.3 & 105 & 35.7 & 189 & 64.3 & \\
\hline N2 & 192 & 21.1 & 69 & 35.9 & 123 & 64.1 & \\
\hline N3 & 125 & 13.7 & 53 & 42.4 & 72 & 57.6 & \\
\hline \multicolumn{8}{|l|}{ Metastasis } \\
\hline MO & 785 & 90.1 & 292 & 37.2 & 493 & 62.8 & \multirow[t]{2}{*}{0.8336} \\
\hline M1 & 86 & 9.9 & 31 & 36.0 & 55 & 64.0 & \\
\hline \multicolumn{8}{|l|}{ Tumor stage } \\
\hline । & 75 & 8.9 & 20 & 26.7 & 55 & 73.3 & \multirow[t]{4}{*}{0.0829} \\
\hline$\|$ & 372 & 44.1 & 135 & 36.3 & 237 & 63.7 & \\
\hline III & 311 & 36.8 & 130 & 41.8 & 181 & 58.2 & \\
\hline IV & 86 & 10.2 & 31 & 36.0 & 55 & 64.0 & \\
\hline \multicolumn{8}{|l|}{ Histologic grade } \\
\hline Well differentiated & 74 & 7.7 & 21 & 28.4 & 53 & 71.6 & \multirow[t]{3}{*}{0.0039} \\
\hline Moderately differentiated & 493 & 51.2 & 159 & 32.2 & 334 & 67.8 & \\
\hline Poorly differentiated & 395 & 41.1 & 156 & 42.0 & 229 & 58.0 & \\
\hline \multicolumn{8}{|l|}{ Histology } \\
\hline Infiltrating ductal carcinoma & 890 & 94.4 & 329 & 37.0 & 561 & 63.0 & \multirow[t]{3}{*}{0.0076} \\
\hline Infiltrating lobular & 40 & 4.2 & 7 & 17.5 & 33 & 82.5 & \\
\hline Mucinous & 13 & 1.4 & 2 & 15.4 & 11 & 84.6 & \\
\hline \multicolumn{8}{|l|}{ Recurrence } \\
\hline Yes & 256 & 29.8 & 104 & 40.6 & 152 & 59.4 & \multirow[t]{2}{*}{0.1225} \\
\hline No & 602 & 70.2 & 211 & 35.1 & 391 & 64.9 & \\
\hline \multicolumn{8}{|l|}{ ER } \\
\hline Negative & 333 & 34.3 & 150 & 45.1 & 183 & 54.9 & \multirow[t]{2}{*}{$<0.0001$} \\
\hline Positive & 638 & 65.7 & 200 & 31.3 & 438 & 68.7 & \\
\hline \multicolumn{8}{|l|}{$P R$} \\
\hline Negative & 412 & 42.5 & 178 & 43.2 & 234 & 56.8 & \multirow[t]{2}{*}{0.0001} \\
\hline Positive & 558 & 57.5 & 172 & 30.8 & 386 & 69.2 & \\
\hline \multicolumn{8}{|l|}{ Triple-negative } \\
\hline Yes & 147 & 15.2 & 69 & 46.9 & 78 & 53.1 & 0.0034 \\
\hline No & 822 & 84.8 & 281 & 34.2 & 541 & 65.8 & \\
\hline HER2 FISH & & & & & & & \\
\hline Amplified & 275 & 29.0 & 108 & 39.3 & 167 & 60.7 & 0.2647 \\
\hline Normal/gain & 672 & 71.0 & 238 & 35.4 & 434 & 64.6 & \\
\hline ALK FISH & & & & & & & \\
\hline Amplified & 126 & 13.3 & 61 & 48.4 & 65 & 51.6 & 0.0031 \\
\hline Normal/gain & 821 & 86.7 & 284 & 34.6 & 537 & 65.4 & \\
\hline
\end{tabular}


Table 2 Correlation of ALK IHC with clinicopathologic parameters in breast cancer (Continued)

\begin{tabular}{|c|c|c|c|c|c|c|c|}
\hline \multicolumn{8}{|l|}{$\mathrm{Ki}-67 \mathrm{IHC}$} \\
\hline High & 818 & 85.8 & 318 & 38.9 & 500 & 61.1 & \multirow[t]{2}{*}{0.0001} \\
\hline Low & 135 & 14.2 & 30 & 22.2 & 105 & 77.8 & \\
\hline \multicolumn{8}{|l|}{$\mathrm{p}-\mathrm{AKT}$} \\
\hline Positive & 212 & 22.6 & 132 & 62.3 & 80 & 37.7 & \multirow[t]{2}{*}{$<0.000$} \\
\hline Negative & 725 & 77.4 & 211 & 29.1 & 514 & 70.9 & \\
\hline \multicolumn{8}{|c|}{ Molecular subtype } \\
\hline HR+Her2- & 460 & 47.4 & 142 & 30.9 & 318 & 69.1 & \multirow[t]{4}{*}{0.0018} \\
\hline $\mathrm{HR}+\mathrm{Her} 2+$ & 232 & 23.9 & 83 & 35.8 & 149 & 64.2 & \\
\hline TNBC & 147 & 15.1 & 69 & 46.9 & 78 & 53.1 & \\
\hline HR-Her2+ & 132 & 13.6 & 56 & 42.4 & 76 & 57.6 & \\
\hline \multicolumn{8}{|l|}{ Survival } \\
\hline OS 5 years & & & & 77.0 & & 82.4 & 0.1212 \\
\hline
\end{tabular}

and MDA-MB231) showed amplification of the ALK gene.

The FISH data on breast cancer cases were further confirmed by qPCR analysis on few selected amplified and non-amplified breast cancer samples (Fig. 2e).

\section{Correlation of ALK gene copy number alteration and clinicopathologic features}

Both ALK FISH and IHC data were available for 947/ 1009 cases. ALK gene amplification had a significant correlation with ALK protein expression $(p=0.0031)$ (Table 3). ALK gene amplification did not show any association with age, lymph node involvement, distant metastasis, molecular subtype of breast cancer and tumor stage. ALK gene amplification was significantly associated with mucinous histology $(p=0.0194)$ and Ki67 expression $(p=0.0129)$.

\section{Survival analysis}

The 5-year overall survival of our patient cohort showing ALK overexpression was lower than patients lacking this overexpression, however this survival difference could not reach significant statistical value $(p=0.1212$, Figure S3 in Additional file 4). Recurrence-free survival was significantly lower for patients with ALK protein overexpression compared to tumors showing low ALK expression ( $p=0.0090)$ (Fig. 3). ALK amplification was also not associated with any significant survival difference.

\section{Discussion}

Breast cancer is one of the most extensively studied malignancies in the world and, despite improvement in the management of this cancer, it still remains a major cause of mortality and morbidity among female cancer patients [42]. Previously, reports have shown that ALK tyrosine kinase receptor is a strong biomarker and a good therapeutic target for a significant number of cancer patients $[43,44]$. Therefore, in order to learn more on the prevalence and clinical significance of ALK overexpression and its association with clinical parameters in Middle Eastern breast cancer, we comprehensively investigated protein expression of ALK and numerical and structural alterations by FISH in a large cohort of breast cancer cases.

There is a wide variation in overexpression of ALK that has been reported in different subtypes of breast cancer. In this study, ALK overexpression was seen in $36 \%$ of Middle Eastern breast cancer cases and this observation is in concordance with an earlier published study showing $47 \%$ of ALK overexpression in a cohort of 100 breast cancer cases [45]. However, ALK overexpression as high as $75 \%$ in infiltrating ductal carcinoma has been reported in a small cohort representing 63 samples from 22 patients [46]. Previously, Perez-Pinera et al. showed ALK overexpression in $50 \%$ of the lobular subtype, whereby, we found ALK overexpression in only $17.5 \%$ of lobular cases in our cohort [46]. Contrarily, Mehrjardi et al. could not find ALK overexpression in any case of lobular subtype in his patient cohort [45].

Significant association of ALK overexpression was seen with triple negative breast cancers (TNBCs). ALK protein was overexpressed in $47 \%$ of TNBC cases, which was significantly higher than in non-TNBC cases. Our results show that the ALK signaling pathway possibly is more common in TNBC. Since TNBC is a poor prognosis breast cancer lacking any molecular target, so 
A

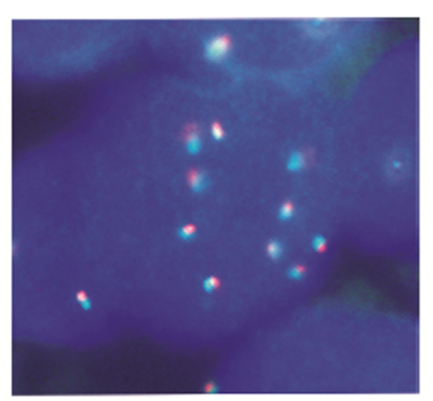

C

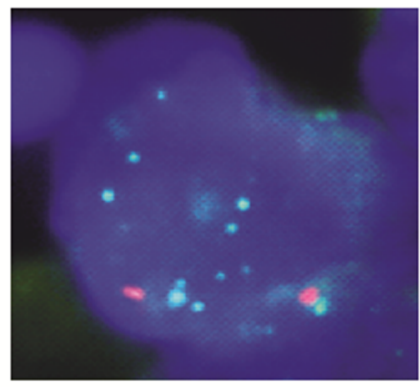

E

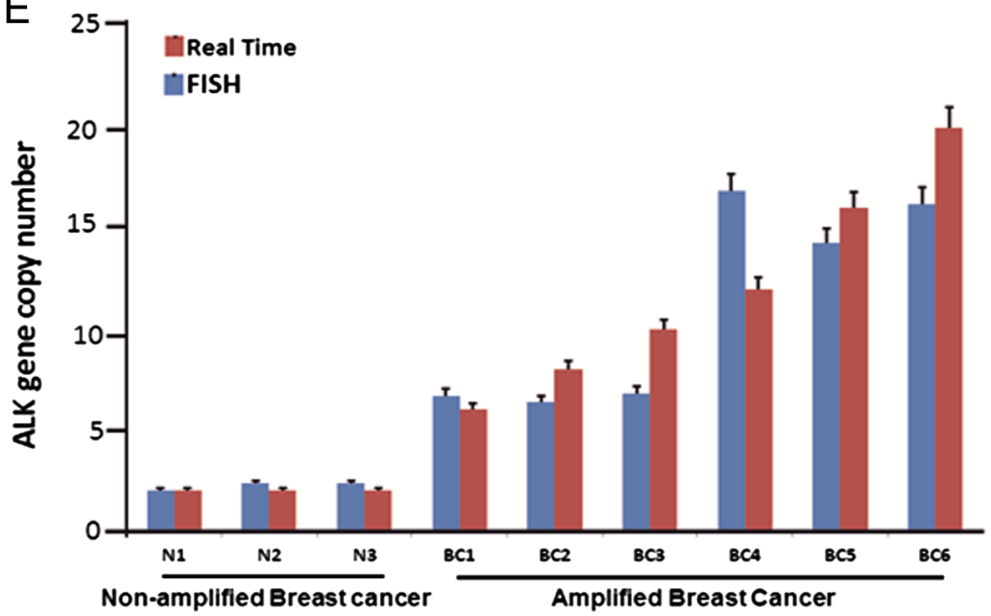

Fig. 2 Determination of ALK gene copy number by fluorescence in situ hybridization. Copy number variation was further validated by an independent method of quantitative PCR in ALK amplified and non-amplified breast cancer samples. Tissues were screened on an Olympus BX 51 microscope (Olympus America Inc, Center Valley, PA, USA) under 100× magnification. a Breast cancer ALK amplified sample hybridized with ALK break-apart probe showing ten red and green fused signals. b Breast cancer ALK non-amplified sample hybridized with ALK breakapart probe showing normal tissue with two red and green fused signals. c Breast cancer ALK amplified sample hybridized with BAC probe RP11-328L16 and CEP2 probe showing two red CEP2 signals and seven to eight green signals representing the ALK gene amplification. d Breast cancer ALK non-amplified sample hybridized with BAC probe RP11-328L16 and CEP2 probe showing two red CEP2 signals and two green signals representing normal ALK copy number. e Verification of the ALK gene copy number by real-time quantitative PCR. Histogram showing ALK gene copy number obtained from normal breast samples 1-3 with two normal copies of ALK gene and samples 4-8 are amplified breast cancer samples. ALK anaplastic lymphoma kinase, $P C R$ polymerase chain reaction

ALK overexpression can be exploited as a possible therapeutic target. ALK overexpression was also seen to be associated with poorly differentiated tumors $(p=0.0039)$ and tumors with a high proliferation index in our patient cohort, showing Ki-67 overexpression to be $42 \%$ $(p=<0.0001)$. The proliferation marker Ki-67 has repeatedly been confirmed as an independent predictive and prognostic factor in early breast cancer [47]. It has been shown that breast cancer with high Ki-67 expression responds better to chemotherapy [48], but is associated with poor prognosis [49]. This phenomenon is similar to the triple-negative paradox, which shows that TNBC had a poorer survival rate, despite a higher response rate to neoadjuvant chemotherapy [50]. In addition, TNBC has been shown to be associated with a higher expression of Ki-67 than non-TNBC [51]. These 
Table 3 Correlation of ALK FISH with clinicopathologic parameters in breast cancer

\begin{tabular}{|c|c|c|c|c|c|c|c|}
\hline & \multicolumn{2}{|c|}{ Total } & \multicolumn{2}{|c|}{ Amplified } & \multicolumn{2}{|c|}{ Non-amplified } & \multirow[t]{2}{*}{$P$ value } \\
\hline & $\mathrm{N}$ & $\%$ & $\mathrm{~N}$ & $\%$ & $\mathrm{~N}$ & $\%$ & \\
\hline Total number of cases & 980 & & 130 & 13.3 & 850 & 86.7 & \\
\hline \multicolumn{8}{|l|}{ Age groups } \\
\hline$<50$ & 666 & 68.0 & 85 & 12.8 & 581 & 87.2 & \multirow[t]{2}{*}{0.5018} \\
\hline$\geq 50$ & 314 & 32.0 & 45 & 14.3 & 269 & 85.7 & \\
\hline \multicolumn{8}{|l|}{ Lymph nodes } \\
\hline NO & 305 & 33.1 & 38 & 12.5 & 267 & 87.5 & \multirow[t]{4}{*}{0.2010} \\
\hline N1 & 295 & 32.1 & 47 & 15.9 & 248 & 84.1 & \\
\hline N2 & 192 & 20.8 & 25 & 13.0 & 167 & 87.0 & \\
\hline N3 & 128 & 13.9 & 11 & 8.6 & 117 & 91.4 & \\
\hline \multicolumn{8}{|l|}{ Metastasis } \\
\hline MO & 789 & 89.7 & 111 & 14.1 & 678 & 85.9 & \multirow[t]{2}{*}{0.5986} \\
\hline M1 & 91 & 10.3 & 11 & 12.1 & 80 & 87.9 & \\
\hline \multicolumn{8}{|l|}{ Tumor stage } \\
\hline । & 77 & 9.0 & 9 & 11.7 & 68 & 88.3 & \multirow[t]{4}{*}{0.7588} \\
\hline$\|$ & 374 & 43.8 & 57 & 15.2 & 317 & 84.8 & \\
\hline III & 311 & 36.5 & 42 & 13.5 & 269 & 86.5 & \\
\hline IV & 91 & 10.7 & 11 & 12.1 & 80 & 87.9 & \\
\hline \multicolumn{8}{|l|}{ Histologic grade } \\
\hline Well differentiated & 74 & 7.6 & 7 & 9.5 & 67 & 90.5 & \multirow[t]{3}{*}{0.3393} \\
\hline Moderately differentiated & 498 & 51.4 & 62 & 12.4 & 436 & 87.6 & \\
\hline Poorly differentiated & 397 & 41.0 & 59 & 14.9 & 338 & 85.1 & \\
\hline \multicolumn{8}{|l|}{ Histology } \\
\hline Infiltrating ductal & 896 & 94.0 & 124 & 13.8 & 772 & 86.2 & \multirow[t]{3}{*}{0.0194} \\
\hline Infiltrating lobular & 44 & 4.6 & 1 & 2.3 & 43 & 97.7 & \\
\hline Mucinous & 13 & 1.4 & 3 & 23.1 & 10 & 76.9 & \\
\hline \multicolumn{8}{|l|}{ Recurrence } \\
\hline Yes & 257 & 29.7 & 42 & 16.3 & 215 & 83.7 & \multirow[t]{2}{*}{0.1569} \\
\hline No & 308 & 70.3 & 77 & 12.7 & 531 & 87.3 & \\
\hline \multicolumn{8}{|l|}{$E R^{*}$} \\
\hline Negative & 332 & 33.9 & 48 & 14.5 & 284 & 85.5 & \multirow[t]{2}{*}{0.4388} \\
\hline Positive & 647 & 66.1 & 82 & 12.6 & 565 & 87.4 & \\
\hline \multicolumn{8}{|l|}{$P R^{*}$} \\
\hline Negative & 408 & 41.9 & 58 & 14.2 & 350 & 75.8 & \multirow[t]{2}{*}{0.4010} \\
\hline Positive & 566 & 58.1 & 70 & 12.4 & 496 & 87.6 & \\
\hline \multicolumn{8}{|l|}{ Triple-negative* } \\
\hline Yes & 141 & 14.5 & 16 & 11.3 & 125 & 88.7 & 0.4848 \\
\hline No & 832 & 85.5 & 112 & 13.5 & 720 & 86.5 & \\
\hline HER2 FISH* & & & & & & & \\
\hline Amplified & 282 & 29.5 & 48 & 17.0 & 234 & 83.0 & 0.0418 \\
\hline Normal/gain & 675 & 70.5 & 81 & 12.0 & 594 & 88.0 & \\
\hline ALK IHC & & & & & & & \\
\hline Present & 345 & 36.4 & 61 & 17.7 & 284 & 82.3 & 0.0031 \\
\hline
\end{tabular}


Table 3 Correlation of ALK FISH with clinicopathologic parameters in breast cancer (Continued)

\begin{tabular}{|c|c|c|c|c|c|c|c|}
\hline Absent & 602 & 63.6 & 65 & 10.8 & 537 & 89.2 & \\
\hline \multicolumn{8}{|l|}{$\mathrm{Ki}-67 \mathrm{IHC}$} \\
\hline High & 825 & 86.3 & 117 & 14.2 & 708 & 85.8 & \multirow[t]{2}{*}{0.0569} \\
\hline Low & 131 & 13.7 & 11 & 8.4 & 120 & 91.6 & \\
\hline \multicolumn{8}{|l|}{$\mathrm{p}-\mathrm{AKT}$} \\
\hline Positive & 210 & 22.4 & 31 & 14.8 & 179 & 85.2 & \multirow[t]{2}{*}{0.4232} \\
\hline Negative & 729 & 77.6 & 92 & 12.6 & 637 & 87.4 & \\
\hline \multicolumn{8}{|c|}{ Molecular subtype } \\
\hline HR+Her2- & 461 & 47.2 & 58 & 12.6 & 403 & 87.4 & \multirow[t]{4}{*}{0.6418} \\
\hline HR+Her2+ & 238 & 24.4 & 33 & 13.9 & 205 & 86.1 & \\
\hline TNBC & 141 & 14.4 & 16 & 11.4 & 125 & 88.6 & \\
\hline HR-Her2+ & 139 & 13.9 & 22 & 16.2 & 114 & 83.8 & \\
\hline \multicolumn{8}{|l|}{ Survival } \\
\hline OS 5 years & & & & 77.3 & & 80.3 & 0.3303 \\
\hline
\end{tabular}

$A L K$ anaplastic lymphoma kinase, FISH fluorescence in situ hybridization, ER estrogen receptor, $P R$ progesterone receptor, $H E R 2$ human epidermal growth factor receptor 2, IHC immunohistochemistry, HR hormone receptor, $T N B C$ triple-negative breast cancer, OS overall survival

*Data was not available (NA) for some cases: Age (NA = 27), Lymph nodes (NA = 72), Metastasis (NA = 100), Stage (NA = 144), Grade (NA = 53), Histology $(\mathrm{NA}=27), \mathrm{ER}(\mathrm{NA}=1), \mathrm{PR}(\mathrm{NA}=6)$, Triple-negative $(\mathrm{NA}=7), \mathrm{HER}-2 \mathrm{FISH}(\mathrm{NA}=23), \mathrm{ALK}$ FISH $(\mathrm{NA}=33), \mathrm{Ki}-67(\mathrm{NA}=24)$

findings suggest that targeting ALK with its inhibitors might have promising therapeutic implications in treating such aggressive breast cancer subtypes especially TNBC, which has increased chances of recurrence and metastasis and poor clinical outcome due to absence of known hormonal and molecular targets.

ALK amplification was seen in $13.3 \%$ of our breast cancer cohort. Previously, Tuma et al. had shown ALK amplification in $75 \%$ of inflammatory breast cancer, however, the study was performed on a very small cohort of 12 cases [18]. The Cancer Genome Atlas (TCGA) dataset has also shown ALK amplification in $9 \%$ of the breast cancer cases [52]. In addition we also

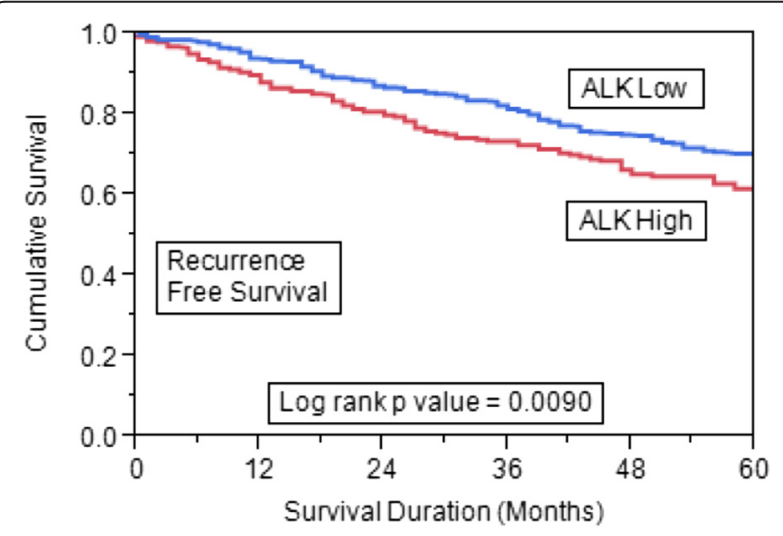

Fig. 3 Kaplan-Meier survival analysis for the prognostic significance of ALK expression in breast cancer. Breast cancer patients with overexpression of ALK had reduced 5-year recurrence-free survival compared with those showing low expression of $\operatorname{ALK}(p=0.0090)$. ALK anaplastic lymphoma kinase sought for EML4-ALK translocation, which has been extensively reported in lung cancer [53]. Interestingly, we were not able to detect any translocation of ALK with the EML4 gene. Similar to our study, Fukuyoshi et al. also could not find this translocation in any of his 90 breast cancer cases tested for this translocation [54]. However, Lin et al. had shown the presence of EML 4-ALK translocation in $2.4 \%(5 / 209)$ of breast cancer cases [12]. Similarly, Robertson et al. had also found this translocation in one case out of 25 inflammatory breast cancer cases studied [21]. The exact cause of this discrepancy is not known, however, one possible reason could be the differences in ethnic population between studies as these authors had studied breast cancers from a Caucasian population while our study was conducted on Middle Eastern breast cancer cases.

ALK protein overexpression was significantly associated with ALK gene amplification in our study $(p=0.0031)$. Even though, there was significant association between ALK IHC and ALK FISH data but there was predominance in cases with protein overexpression compared to gene amplification (36\% versus $13.3 \%$ ). This difference could be partially attributed to the dependence of ALK expression on other signaling pathways, which had been previously hypothesized [55]. An alternative reason could be the presence of other translocation fusion partners with the ALK gene leading to ALK overexpression [56]. Moreover, the role of ALK mutations in causing protein overexpression cannot be ruled out as one of the possible mechanisms, as previously documented in neuroblastoma [57]. However, further studies are needed to explain these observations. 
Another interesting observation was the strong association between ALK overexpression and p-AKT in our study $(p<0.0001)$. The $\mathrm{p}-\mathrm{AKT}$ signaling pathway is activated in different types of cancers [58]. This molecular correlation with the AKT pathway has also been shown previously in ALK-expressing ALCL [59]. The use of mTOR/AKT inhibitors along with ALK inhibitors have also been recently justified in ALK-altered neuroblastoma [60]. Therefore, it is hypothesized that ALK has a possible role in breast carcinogenesis via the AKT signaling pathway.

\section{Conclusions}

In conclusion, we have comprehensively investigated the ALK alterations in a large cohort of breast cancer cases. ALK overexpression is present in a substantial proportion of breast cancer cases and is significantly associated with aggressive tumor parameters. ALK gene amplification accounts for a significant proportion of this protein overexpression and the role of other possible mechanisms are hypothesized. ALK inhibitors alone or in combination can be exploited as a novel therapeutic agent in aggressive subtypes of breast cancers. Further studies are required to validate these observations.

\section{Additional files}

Additional file 1: Table S1. Details of primary antibodies used in the study. Details of primary antibodies used in the study including antibody clone, manufacturer and dilution used for each antibody.

Additional file 2: Figure S1. Biochemical fractionation of ALK expression in breast cancer cell lines. (A) Nuclear-free cytosolic and nuclear extracts were isolated from MDA-MB231 and MCF12A cells and immunoblotted with antibodies against ALK and tubulin. (B) Relative expression of ALK was calculated using spot densitometry on cytosolic and nuclear immunoblots of MDA-MB231 and MCF12A cells. Expression of ALK was normalized with tubulin.

Additional file 3: Figure S2. ALK expression in triple-negative breast cancer cell line versus normal cell line. (A) Total proteins isolated from MDA-MB231 and MCF12A cells were immunoblotted with antibodies against ALK and beta-actin. (B) Relative expression of ALK was calculated using spot densitometry on total protein immunoblots of MDA-MB231 and MCF12A cells. Expression of ALK was normalized with beta-actin.

Additional file 4: Figure S3. Kaplan-Meier survival analysis for overall survival of ALK expression in breast cancer. Breast cancer patients with overexpression of ALK had reduced overall survival at 5 years compared with low expression of ALK, although not significant $(p=0.1212$ ).

\section{Abbreviations}

ALCL: anaplastic large cell lymphoma; ALK: anaplastic lymphoma kinase; ER: estrogen receptor; FISH: fluorescence in situ hybridization; HER2: human epidermal growth factor receptor 2; IHC: immunohistochemistry; LINE1: long interspersed element 1; PR: progesterone receptor; qRT-PCR: quantitative real-time polymerase chain reaction; TNBC: triple-negative breast cancer.

\section{Competing interests}

All authors declare that they have no competing interests.

\section{Authors' contributions}

AKS reviewed and analyzed the clinical data and did the critical revision of the manuscript. SB analyzed the IHC data, did statistical analysis and drafted the manuscript. SP prepared the TMA, performed the IHC screening and analyzed the data. ZJ performed the FISH experiments and analyzed FISH data, and drafted the manuscript. MA and ARH performed cell line experiments and analyzed the data. FAD, AT and DA reviewed and analyzed pathological and clinical data. KSA designed the study, analyzed the data and drafted the manuscript. All authors read and approved the final manuscript.

\section{Acknowledgments}

We thank Valorie Balde, Padmanaban Annaiyappanaidu, and Zeeshan Qadri for their technical assistance.

\section{Author details}

'Department of Human Cancer Genomic Research, King Faisal Specialist Hospital and Research Center, Makkah Al Mukarramah Branch Road, Riyadh 12713, Saudi Arabia. ${ }^{2}$ Department of Pathology, King Faisal Specialist Hospital and Research Center, Makkah Al Mukarramah Branch Road, Riyadh 12713, Saudi Arabia. ${ }^{3}$ Oncology Center, King Faisal Specialist Hospital and Research Center, Makkah Al Mukarramah Branch Road, Riyadh 12713, Saudi Arabia. ${ }^{4}$ Department of Pathology, Al-Faisal University, Al Zahrawi Street, Riyadh 11533, Saudi Arabia.

Received: 2 March 2015 Accepted: 7 July 2015

Published online: 17 September 2015

\section{References}

1. Stagg J, Allard B. Immunotherapeutic approaches in triple-negative breast cancer: latest research and clinical prospects. Ther Adv Med Oncol. 2013;5:169-81.

2. Tavassoli FA, Devilee P. World Health Organization classification of tumours, pathology and genetics of tumours of the breast and female genital organs. Lyon, France: International Agency for Research on Cancer Press; 2003.

3. Bazarbashi S. Cancer Incidence Report Saudi Arabia. Riyadh (KSA): Saudi Cancer Registry; 2010. p. 18-21.

4. Al Tamimi DM, Shawarby MA, Ahmed A, Hassan AK, AlOdaini AA. Protein expression profile and prevalence pattern of the molecular classes of breast cancer-a Saudi population based study. BMC Cancer. 2010;10:223.

5. Al-Kuraya K, Schraml P, Sheikh S, Amr S, Torhorst J, Tapia C, et al. Predominance of high-grade pathway in breast cancer development of Middle East women. Mod Pathol. 2005;18:891-7.

6. Autier P, Boniol M, La Vecchia C, Vatten L, Gavin A, Héry C, et al. Disparities in breast cancer mortality trends between 30 European countries: retrospective trend analysis of WHO mortality database. BMJ. 2010;341:c3620.

7. Morris SW, Kirstein MN, Valentine MB, Dittmer KG, Shapiro DN, Saltman DL, et al. Fusion of a kinase gene, ALK, to a nucleolar protein gene, NPM, in non-Hodgkin's lymphoma. Science. 1994;263:1281-4.

8. Takeuchi K, Choi YL, Togashi Y, Soda M, Hatano S, Inamura K, et al. KIF5BALK, a novel fusion oncokinase identified by an immunohistochemistrybased diagnostic system for ALK-positive lung cancer. Clin Cancer Res. 2009;15:3143-9.

9. Takeuchi K, Soda M, Togashi Y, Suzuki R, Sakata S, Hatano S, et al. RET, ROS1 and ALK fusions in lung cancer. Nat Med. 2012;18:378-81.

10. Debelenko LV, Raimondi SC, Daw N, Shivakumar BR, Huang D, Nelson M, et al. Renal cell carcinoma with novel VCL-ALK fusion: new representative of ALK-associated tumor spectrum. Mod Pathol. 2011;24:430-42.

11. Hernandez L, Pinyol M, Hernandez S, Beà S, Pulford K, Rosenwald A, et al. TRK-fused gene (TFG) is a new partner of ALK in anaplastic large cell lymphoma producing two structurally different TFG-ALK translocations. Blood. 1999;94:3265-8.

12. Lin E, Li L, Guan Y, Rivers CS, Mohan S, Pandita A, et al. Exon array profiling detects EML4-ALK fusion in breast, colorectal, and non-small cell lung cancers. Mol Cancer Res. 2009;7:1466-76.

13. Soda M, Choi YL, Enomoto M, Takada S, Yamashita Y, Ishikawa S, et al. Identification of the transforming EML4-ALK fusion gene in non-small-cell lung cancer. Nature. 2007;448:561-6.

14. Chen Y, Takita J, Choi YL, Kato M, Ohira M, Sanada M, et al. Oncogenic mutations of ALK kinase in neuroblastoma. Nature. 2008:455:971-4.

15. George RE, Sanda T, Hanna M, Fröhling S, Luther 2nd W, Zhang J, et al. Activating mutations in ALK provide a therapeutic target in neuroblastoma. Nature. 2008:455:975-8. 
16. Janoueix-Lerosey I, Lequin D, Brugieres L, Ribeiro A, de Pontual L, Combaret $\checkmark$, et al. Somatic and germline activating mutations of the ALK kinase receptor in neuroblastoma. Nature. 2008;455:967-70.

17. Salido M, Pijuan L, Martinez-Aviles L, Galván AB, Cañadas I, Rovira A, et al. Increased ALK gene copy number and amplification are frequent in nonsmall cell lung cancer. J Thorac Oncol. 2011;6:21-7.

18. Tuma RS. ALK gene amplified in most inflammatory breast cancers. J Natl Cancer Inst. 2012;104:87-8.

19. van Gaal JC, Flucke UE, Roeffen MH, de Bont ES, Sleijfer S, MavinkurveGroothuis AM, et al. Anaplastic lymphoma kinase aberrations in rhabdomyosarcoma: clinical and prognostic implications. J Clin Oncol. 2012;30:308-15.

20. Powers C, Aigner A, Stoica GE, McDonnell K, Wellstein A. Pleiotrophin signaling through anaplastic lymphoma kinase is rate-limiting for glioblastoma growth. J Biol Chem. 2002;277:14153-8.

21. Robertson FM, Petricoin lii EF, Van Laere SJ, Bertucci F, Chu K, Fernandez SV, et al. Presence of anaplastic lymphoma kinase in inflammatory breast cancer. Springerplus. 2013;2:497.

22. van Uden DJ, van Laarhoven HW, Westenberg AH, de Wilt JH, BlankenPeeters CF. Inflammatory breast cancer: an overview. Crit Rev Oncol Hematol. 2015:93:116-26.

23. Jasgit CS, Pranitha N, Rafael AB, Namratha V. Anaplastic lymphoma kinase (ALK): A potential oncogenic driver in triple-negative breast cancer? J Clin Oncol. 31, 2013 (suppl; abstr 1067).

24. Butrynski JE, D'Adamo DR, Hornick JL, Dal Cin P, Antonescu CR, Jhanwar SC, et al. Crizotinib in ALK-rearranged inflammatory myofibroblastic tumor. N Engl J Med. 2010;363:1727-33.

25. Du XL, Hu H, Lin DC, Xia SH, Shen XM, Zhang Y, et al. Proteomic profiling of proteins dysregulated in Chinese esophageal squamous cell carcinoma. J Mol Med (Berl). 2007;85:863-75.

26. Kwak EL, Bang YJ, Camidge DR, Shaw AT, Solomon B, Maki RG, et al. Anaplastic lymphoma kinase inhibition in non-small-cell lung cancer. N Engl J Med. 2010;363:1693-703.

27. Azarova AM, Gautam G, George RE. Emerging importance of ALK in neuroblastoma. Semin Cancer Biol. 2011;21:267-75.

28. Grob TJ, Heilenkotter U, Geist S, Paluchowski P, Wilke C, Jaenicke F, et al. Rare oncogenic mutations of predictive markers for targeted therapy in triple-negative breast cancer. Breast Cancer Res Treat. 2012;134:561-7.

29. Morales La Madrid A, Campbell N, Smith S, Cohn SL, Salgia R. Targeting ALK: a promising strategy for the treatment of non-small cell lung cancer, nonHodgkin's lymphoma, and neuroblastoma. Target Oncol. 2012;7:199-210.

30. Thunnissen E, Bubendorf L, Dietel M, Elmberger G, Kerr K, Lopez-Rios F, et al. EML4-ALK testing in non-small cell carcinomas of the lung: a review with recommendations. Virchows Arch. 2012;461:245-57.

31. Sun JM, Choi YL, Won JK, Hirsch FR, Ahn JS, Ahn MJ, et al. A dramatic response to crizotinib in a non-small-cell lung cancer patient with $\mathrm{HC}$ positive and FISH-negative ALK. J Thorac Oncol. 2012;7:e36-8.

32. Jehan Z, Bavi P, Sultana M, Abubaker J, Bu R, Hussain A, et al. Frequent PIK3CA gene amplification and its clinical significance in colorectal cancer. J Pathol. 2009;219:337-46.

33. Ensembl Genome Browser 75. http://grch37.ensembl.org/index.html. Accessed on 2 Mar 2014.

34. Abubaker J, Jehan Z, Bavi P, Sultana M, Al-Harbi S, Ibrahim M, et al. Clinicopathological analysis of papillary thyroid cancer with PIK3CA alterations in a Middle Eastern population. J Clin Endocrinol Metab. 2008;93:611-8.

35. Abubaker J, Bavi P, Al-Haqawi W, Sultana M, Al-Harbi S, Al-Sanea N, et al. Prognostic significance of alterations in KRAS isoforms KRAS-4A/4B and KRAS mutations in colorectal carcinoma. J Pathol. 2009:219:435-45.

36. Pfaffl MW, Horgan GW, Dempfle L. Relative expression software tool (REST) for group-wise comparison and statistical analysis of relative expression results in real-time PCR. Nucleic Acids Res. 2002;30, e36.

37. Mino-Kenudson M, Chirieac LR, Law K, Hornick JL, Lindeman N, Mark EJ, et al. A novel, highly sensitive antibody allows for the routine detection of ALK-rearranged lung adenocarcinomas by standard immunohistochemistry. Clin Cancer Res. 2010;16:1561-71.

38. Deyarmin $B$, Kane $J \mathrm{~L}$, Valente $A L$, van Laar $R$, Gallagher $C$, Shriver $C D$, et al. Effect of ASCO/CAP guidelines for determining ER status on molecular subtype. Ann Surg Oncol. 2013;20:87-93.

39. Abd-Elazeem MA. Claudin 4 expression in triple-negative breast cancer: correlation with androgen receptors and Ki-67 expression. Ann Diagn Pathol. 2015;19:37-42.
40. Al-Bazz YO, Underwood JC, Brown BL, Dobson PR. Prognostic significance of Akt, phospho-Akt and BAD expression in primary breast cancer. Eur J Cancer. 2009;45:694-704.

41. Camp RL, Dolled-Filhart M, Rimm DL. X-tile: a new bio-informatics tool for biomarker assessment and outcome-based cut-point optimization. Clin Cancer Res. 2004;10:7252-9.

42. Ekwueme DU, Guy Jr GP, Rim SH, White A, Hall IJ, Fairley TL, et al. Health and economic impact of breast cancer mortality in young women, 1970-2008. Am J Prev Med. 2014;46:71-9.

43. Kelleher FC, McDermott R. The emerging pathogenic and therapeutic importance of the anaplastic lymphoma kinase gene. Eur J Cancer. 2010;46:2357-68.

44. Grande E, Bolos MV, Arriola E. Targeting oncogenic ALK: a promising strategy for cancer treatment. Mol Cancer Ther. 2011:10:569-79.

45. Mehrjardi AZ, Vaghefi A. Expression of anaplastic lymphoma kinase protein in human breast cancer. Iran J Pathol. 2013;8(1):27-35.

46. Perez-Pinera P, Chang Y, Astudillo A, Mortimer J, Deuel TF. Anaplastic lymphoma kinase is expressed in different subtypes of human breast cancer. Biochem Biophys Res Commun. 2007;358:399-403.

47. Urruticoechea A, Smith IE, Dowsett M. Proliferation marker Ki-67 in early breast cancer. J Clin Oncol. 2005;23:7212-20.

48. Jones RL, Salter J, A'Hern R, Nerurkar A, Parton M, Reis-Filho JS, et al. Relationship between oestrogen receptor status and proliferation in predicting response and long-term outcome to neoadjuvant chemotherapy for breast cancer. Breast Cancer Res Treat. 2010;119:315-23.

49. Jung SY, Han W, Lee JW, Ko E, Kim E, Yu JH, et al. Ki-67 expression gives additional prognostic information on St. Gallen 2007 and Adjuvant! Online risk categories in early breast cancer. Ann Surg Oncol. 2009;16:1112-21.

50. Carey LA, Dees EC, Sawyer L, Gatti L, Moore DT, Collichio F, et al. The triple negative paradox: primary tumor chemosensitivity of breast cancer subtypes. Clin Cancer Res. 2007;13:2329-34.

51. Keam B, Im SA, Kim HJ, Oh DY, Kim JH, Lee SH, et al. Prognostic impact of clinicopathologic parameters in stage $\|/\| \|$ breast cancer treated with neoadjuvant docetaxel and doxorubicin chemotherapy: paradoxical features of the triple negative breast cancer. BMC Cancer. 2007;7:203.

52. The Cancer Genome Atlas Network. Comprehensive molecular portraits of human breast tumours. Nature. 2012;490:61-70.

53. Rodig SJ, Mino-Kenudson M, Dacic S, Yeap BY, Shaw A, Barletta JA, et al. Unique clinicopathologic features characterize ALK-rearranged lung adenocarcinoma in the western population. Clin Cancer Res. 2009;15:5216-23.

54. Fukuyoshi $Y$, Inoue H, Kita Y, Utsunomiya T, Ishida T, Mori M. EML4-ALK fusion transcript is not found in gastrointestinal and breast cancers. $\mathrm{Br} J$ Cancer. 2008;98:1536-9.

55. Perez-Pinera P, Zhang W, Chang Y, Vega JA, Deuel TF. Anaplastic lymphoma kinase is activated through the pleiotrophin/receptor protein-tyrosine phosphatase beta/zeta signaling pathway: an alternative mechanism of receptor tyrosine kinase activation. J Biol Chem. 2007;282:28683-90.

56. Yokoyama N, Miller WT. Molecular characterization of WDCP, a novel fusion partner for the anaplastic lymphoma tyrosine kinase ALK. Biomed Rep. 2015:3:9-13.

57. Cazes A, Lopez-Delisle L, Tsarovina K, Pierre-Eugène C, De Preter K Peuchmaur $M$, et al. Activated Alk triggers prolonged neurogenesis and Ret upregulation providing a therapeutic target in ALK-mutated neuroblastoma. Oncotarget. 2014;5:2688-702.

58. Polivka Jr J, Janku F. Molecular targets for cancer therapy in the PI3K/AKT/ mTOR pathway. Pharmacol Ther. 2014;142:164-75.

59. Thakral C, Hutchison RE, Shrimpton A, Barrett D, Laver J, Link M, et al. ALK+ anaplastic large cell lymphoma exhibits phosphatidylinositol-3 kinase/Akt activity with retained but inactivated PTEN-a report from the Children's Oncology Group. Pediatr Blood Cancer. 2012;59:440-7.

60. Moore NF, Azarova AM, Bhatnagar N, Ross KN, Drake LE, Frumm S, et al. Molecular rationale for the use of PI3K/AKT/mTOR pathway inhibitors in combination with crizotinib in ALK-mutated neuroblastoma. Oncotarget. 2014:5:8737-49. 